tion of non-ionic detergent was increased the concentration of inorganic salt required to produce flocculation also increased. Above the critical micelle concentration of the detergent, however, a large increase in stability of the sol occurred. Below the critical micelle concentration the increase in stability was attributed to the increase in hydration of the sol particles caused by adsorption of a thin layer of detergent molecules. The large increase in stability observed above the critical micelle concentration was considered to be due to the fact that the adsorbed molecules prevented the particles from approaching sufficiently closely to enter the primary minimum.

On September 21, the session was entitled "Micellization", and the chair was taken by Prof. D. D. Eley. The first paper in this session, by Dr. A. S. C. Lawrence and Messrs. R. Aveyard and J. T. Pearson (University of Sheffield), presented the results of studies on micellization using calorimetry. Results were presented for micellization and co-micellization (the case of a polar micelle incorporating amphiphilic molecules) and also for the effects of salt concentration on these phenomena. The heats of solution of a series of $n$-alcohols in water and in soap-water mixtures were discussed in terms of the heats of hydration of the hydrocarbon chain and the polar or ionic head group. The contribution to the energy terms due to increased unbinding of counter-ions in the co-micellization process was discussed, and the calorimetric measurements were supported by measurements of conductance, $p \mathrm{H}$ and sodium ion activity in these systems; the latter measurements involved the use of a sodium responsive glass electrode.

Mr. J. Clifford and Dr. B. A. Pethica (Unilever, Port Sunlight) reported the results of measurements on the self-diffusion of micelles of sodium dodecyl sulphate (dye labelled) and on the self-diffusion of sodium ions (radio-tracer labelled) in the presence of these micelles. The mechanism of binding counterions to the micelle by means of electrostatic forces was discussed. The results of some preliminary studies on micelles using nuclear magnetic resonance were also presented. A change in spin lattice relaxation time of the water protons was found in the presence of the micelles, suggesting that water had been immobilized near the micelle surface. The spin lattice relaxation time of the protons in the $\mathrm{CH}_{2}$ groups in the interior of the micelles was approximately ten times shorter than the relaxation time of $\mathrm{CH}_{2}$ groups in liquid hydrocarbons. This suggested that the alkyl chains in the interior of the micelle were under compression.

The structure and stability of black foam films were discussed by Dr. J. F. Goodman (Procter and Gamble, Ltd., Newcastle upon Tyne). Experiments were described in which simultaneous measurements were made of the total film thickness, using an optical method, and of the water content using infrared spectroscopy. The detergent content of the film was determined by radio-tracer experiments. It was shown that the black film (50-100 $\AA$ thick) has a simple lamellar structure in which two monolayers of surface-active molecules are spread on a thin aqueous core. In mixed cationic-anionic surfaceactive systems it was found that the ratio of anionic to cationic material in the film was always $1: 1$, irrespective of the ratio in the bulk liquid. Under these conditions it appeared unlikely that the film could be stabilized by electrostatic repulsion between opposing monolayers of soap ions. The factors influencing the stability of the thin films were discussed in terms of the evaporative equilibrium of the volatile film component. It was suggested that the stability of a black film could be maintained by an excess of solute, relative to the bulk solution, in the aqueous film core.

Prof. B. Stuke (University of Munich, Germany) discussed the thermodynamics of micellar systems. In the first part of the paper a discussion was given of the respective merits of using the law of mass action to describe micellization and of considering the micelle as a separate phase. It was concluded that thermodynamically the law of mass action gives the sound approach, the phase approach being only an approximation. Starting from a model for the process of micelle formation at interfaces the second part of the paper was concerned with the influence of micelles on the stabilization of thin films.

R. H. OTTEWILL

G. D. ParfitT

\title{
GEOLOGY AND GEOPHYSICS IN THE U.S.S.R.
}

$\mathrm{T}$ HE following are abstracts of geological topics that appeared in the Soviet journal Priroda during 1962; for convenience they aro arranged under general headings (in italies).

Tungusska 'meteorite'. The so-called Tungusska 'meteorite', which fell in Siberia $\left(60^{\circ} 55^{\prime} \mathrm{N}\right.$., $101^{\circ} 57^{\prime}$ W.) on June 30,1908 , is once more in the news as the results of the 1961 expedition are made known. This expedition remapped the directions of the fallen trees over an area of $2,000 \mathrm{~km}^{2}$, and located and investigated the nature of the so-called 'impact' craters and the composition of spherical granules extracted from the ground. According to the conclusions of V. G. Fesenkov (Priroda, 8, 24; 1962) and K. P. Florensky and I. T. Zotkin (Priroda, 8, $31 ; 1962)$, the impact was not that of a meteorite but of a comet which struck the Earth at a glancing angle and exploded. However, according to N. I. Piavchenko (Priroda, 8, 39; 1962) the observed cavities in the peat bog are not due to impact but to ordinary processes occurring in regions of permafrost.
Meteorite crater in Sayan Range. According to M. V. Voroshilov (Priroda, 3, 107; 1962) an elliptical hollow, rimmed by a 'bulge' and filled by a lake, some $150-400 \mathrm{~m}$ in diameter, situated on the eastern foothills of the Western Sayan Range, represents a meteorite erater. The author suggests that the meteorite responsible for this hollow fell about 150 years ago.

Biogeochemistry. Recent research in biogeochemistry carried out in the U.S.S.R., including the part played by micro-elements in animal nutrition, rational compensatory feeding and biogeochemical provinces and zones, is discussed by V. V. Kovalsky in the June issue of Priroda $(6,3 ; 1962)$.

Arctic regions. A brief review of recent expeditions to the Soviet Arctic has been made by B. A. Kremer (Priroda, 6, 61; 1962), while an up-to-date general account of the geology of the Arctic region is provided by Y. M. Pushcharovsky (Priroda, 4, 35; 1962). The latter article contains a reduced version of a tectonic map of this region compiled by the 
members of the Institute of Geology of the Arctic. In the descriptive part, the author provides a brief geological-toctonic account based on recent publications in the U.S.S.R., Finland, Norway, Greenland and Canada.

Elbrus. According to J. Y. Panteleev and Y. P. Masurenkov (Priroda, 5, 61; 1962), Elbrus (5,630 m) - the highest mountain in Europe-is not an extinct volcano, but only dormant. This is testified by its extensive fumarolic field giving out numerous steam and gas omanations under its ico cap. The principal gasos emitted are carbon dioxide, chlorine, fluorine and boron compounds. Some emanations are $200^{\circ}-300^{\circ} \mathrm{C}$ at their source.

Geothermy. The first All-Union Conference on the problums of geothermy was held in Moscow during March 1-6, 1956, and the transactions, edited by V. I. Vlodavets and others, were published in the form of two volumes entitled "Problems of Geothermy and Practical Utilization of the Hoat of the Earth" (Pub. Acaut. Sci. U.S.S.R., 1; 1959; 2; 1961). The first volume contains 22 articles, including contributions by I. D. Dergunov, E. A. Lyubimova (both dealing with the thormal rogime and history of the Earth), B. N. Dostovalov (the thermodynamic study of the Earth), V. I. Vlodavets (the hydrothermal regions of Italy and New Zealand) and A. M. Zhirmunsky (problems of geothermo-energotics). These volumes also contain sections dealing with problems of regional geothermy and methods of geothermal studies. The second volume contains 26 articles dealing with problems of hydrogeothermy and dctailed regional investigations of hydrothermal regions of the Soviet Union. One of the articics, by S. A. Dzhamalov, deals with the thermal waters in Dag. hestan. In a more popular articlo (Priroda, 6, 74; 1961) the same author describes the progross made in the utilization of thermal waters in Makhach-Kala, the capital of Daghestan. This town has alroady six active boreholes supplying $4,000 \mathrm{~m}^{3}$ of water at $55^{\circ}-68^{\circ} \mathrm{C}$ per $24 \mathrm{~h}$. This water is used for heating and supply of hot water for domostic and industrial noods. A new borohole is projected to supply $2,000 \mathrm{~m}^{3}$ of wator up to $160^{\circ} \mathrm{C}$ per $24 \mathrm{~h}$ to a geothermal power station.

Geocryology. Geocryology, or the science of permafrost, as studied in a special Institute of the Acaderny of Science, U.S.S.R., is of great importance due to its wide application in the Soviet Union, especially in connexion with buildings, canals and roads. A brief account of permafrost in the Union, illustrated by a new geocryological map, has beon provided by I. A. Nekrasov (Priroda, 2, 19; 1962).

Slow movements of the Earth's crust. In 1960, at the seventh genoral assembly of the International Union of Geodesy and Geophysics held in Holsinki, a special commission for the study of micropulsation and slow movements of the Earth's crust was ostablished, under the chairmanship of Y. A. Mosheheryakov. Various aspects of this work are presented by L. E. Setunskaya (Priroda, 3, 27; 1962) and V. F. Bonchkovsky (Priroda, 7, 48; 1962), whilo V. V. Lamakin (Priroda, 7, 53; 1962) discusses the slow movoments of the Earth's crust in the region of Lake Baikal.

Geochronology. Much work is being carried out in the Soviot Union on goochronology. Rocent research in this field is summed up by I. E. Starik and E. V. Sobotovich (Priroda, 5, 75; 1962), who provide a summary date of absolute age for the geological periods. They also conclude that the ancient parent matter of meteorites is 4,500 million years old, while the minimum age of the Earth is of the order of 3,500 million years. In another article, V. V. Cherdyntzev (Priroda, 6, 42; 1962) gives an account of the origin and dovelopmont of the potassium-argon mothod of geochronology. This method was originally domonstrated by V. G. Khlopin and E. K. Gerling and rapidly developed by numerous research workers, among whom was prominent the group led by A. A. Polkanov in the Laboratory for the Study of the Precambrian at Leningrad. At the present time, more than twenty laboratories carrying out 'potassium-argon' measuroments for dating are functioning in the U.S.S.R.

\section{S. I. TOMKRIEFF}

\section{THE ATOMIC ENERGY COMMISSION OF JAPAN}

$\mathrm{T}$ HE fifth annual report of the Atornic Enorgy Commission of Japan, which was ostablished in 1956, is the first to be published in English*. It describes in some dotail the aims and activities of the Commission and its subsidiary organizations, the Japan Atomic Energy Research Instituto (JAERI), the Atomic Fuel Corporation (AFC) and the National Institute of Radiological Sciences (NIRS). The total number of ernployees of these organizations now exceeds 1,900. About 60 per cent of the Governmental budget (about 8.000 million yon) for atomic energy is allocated to JAERI. The Research Institute has three reactors: $J R R-1$, which has continued normal operation during the yoar under reviow; JRR-2 which reached eriticality during October 1960 and which is used by private companies and universities; and JRR.3, which was due to bo comploted during Septembor 1961 and to become critical by March 1962. The Japan power demonstration reactor $(J P D R)$ is being constructed by the General Electric

* Japan. Atornic Energy Commisgion. Fifth Annual Report, 1196061. Pp. iv +167 . (Tukyo: Atomic Energy Bureau, science and Technology Ageucy, 196:)
Co., United States, and the construction of JRR-4 (shielding research reactor) by JAERI was to be completed by the end of the fiscal year 1961. Reactors are under construction also at Rikkyo University, the Musashi Institute of Technology and Kinki University. Among the private concerns, both Hitachi. Ltd., and Tokyo Shibaura Co., Ltd., have decided to build traininir reactors and to gain atomic energy experience under Government subsidy. During August 1960, the JAERI concluded a contract for the purchase of a $B W R$-type power demonstration reactor.

On February 8, 1961, the Commission announced a new long-range programme of nuclear power genera. tion. On the assumption that nuclear power will become competitive with thermal power in cost in about 1970, it is estimated that new power-generating capacity of $36,000 \mathrm{MTV}$ will be required between 1961 and 1970 , and 48.000 MW between 1971 and 1980 , and that of this $1,000 \mathrm{MW}$ and $6,000-8,000 \mathrm{MW}$ will bo provided by nucloar power plants during the respective decades. Private companios are expected to install tho nuclear power stations, which will be 